\title{
Study of Water Retention Measurement on Concrete Using Paper Filter Whatman No.42
}

\author{
Deris Faisa Ralindra ${ }^{1}$, Ria Asih Aryani Soemitro ${ }^{1}$, Indarto ${ }^{1}$, and Ridho Bayuaji ${ }^{1}$
}

\begin{abstract}
This study aimed to know water retention on concrete using paper filter Whatman No.42. The study was conducted as experimental in laboratory by making two types of specimen with different Water Cement Ratio (WCR); 0.5 and 0.6. Each specimen was immersed for 28 days. Next step was finding the time of consistency water content on specimen and paper filter. Then, water retention could be measured. As a validation of water retention measurement, so the results were compared with saturated salt solution method in dessicator. This study used $\mathrm{NaCl}, \mathrm{KCl}$, and $\mathrm{H} 2 \mathrm{SO} 4$ as saturated salt solution. The results of water retention measurement were shown in graphs.
\end{abstract}

Keywords-Water Retention, Paper Filter Whatman No.42, Porosity, Concrete, Saturated Salt Solution.

\section{INTRODUCTION}

Concrete is a porous material that has very small pore diameter that allows a capillary rise or well known as water retention. Indarto (1991) divided water retention into two parts, namely loading method and measurement method. The loading method is extending capillary stress on sample that has certain initial condition, then wait until the specimens reach stability to extending of capillary stress. Measurement method is a measurement of capillary stress scale of sample that has a certain capillary stress.

Filter paper Whatman No.42 method is a calculation of water retention by measurement method. The filter paper method is an indirect method based on the hypothesis that when a balance occurs, the negative pore pressure in a soil or specimen and a filter paper having contact with the specimen is the same. The filter paper method was first proposed by Gardner (1937. Calibration by Whatman No.42 method was done by Fawcett \& Collis George (1967) and Zerhouni (1991) on wetting. Meanwhile Parcevoux (1980) and Indarto (1991) calibrate the same type of filter paper but on drying. The paper filter method is commonly used because of its relatively fast implementation and cheap cost. In addition, the use of this filter paper provides a wider range that allows it to be used to measure water retention in concrete.

Sebastien Schneider et al. (2012) did a research using two kinds of specimens, consist of concrete and mortar with certain composition. There are two parts for the research. In the first part, estimating parameters of Van Genuchten

\footnotetext{
${ }^{1}$ Deris Faisa Ralindra, Ria Asih Aryani Soemitro, Indarto, and Ridho Bayuaji are with Department of Civil Engineering, Institut Teknologi Sepuluh Nopember, Surabaya, 60111, Indonesia. E-mail: derisralindra@gmail.com; ria@ce.its.ac.id; indarto@ce.its.ac.id;
} bayuaji@ce.its.ac.id. water retention curve based on experimental moisture relation data include both wetting and drying. In the second part, capillary absorption experiments were performed to numerical simulations. To obtain data of experimental water retention, estimating parameters from the calibration of Van Genuchten model. Figure 1 presents water retention curve. The result of fitted van Genuchten parameters for the wetting curve, it will be used to define parameter ranges. It be used by on genetic algorithm for based of inverse modelling. Modelling approach use HYDRUS software pocket.

As a validation of water retention measurement results, then also used loading method with saturated salt solution in dessicator. In this method, the vapor pressure is charged in a vacuum seal, which contains several specimens. Water content of the specimen will decrease or rise, until a balance is reached. The principle of this method was realized in a dessicator containing a saturated salt solution. The saturated salt solution allows in provide and maintain a certain vapor pressure which can be regulated through the original salt and its concentration. Air is removed from dessicator to accelerate the movement of water molecules. This method is used for stress loading less than $-2500 \mathrm{kPa}$.

This paper described the method of concrete water retention measurement using filter paper Whatman No.42 with Water Cement Ratio (WCR) 0.5 and 0.6. The research was conducted as experiment in material and building structure laboratory ITS. The measurement of water retention for each WCR will be done to get sample moisture and plot it in to calibration graph of filter paper. As a validation of the results of water retention measurement, so the result will be compared with saturated salt solutions method in a dessicator. Solution of saturated salt uses $\mathrm{NaCl}, \mathrm{KCl}$, dan $\mathrm{H} 2 \mathrm{SO} 4$. This method took a long time and relatively more expensive. In addition, there were also test of permeability, porosity, UPV, and compressive strength, and then correlating all test result.

\section{METHOD}

\section{A. Making Specimens}

The percentage of mixture to be achieved refer to the mix design that has been done by laboratory of material and building structure at ITS. For FAS 0.5, the mixture ratio was 1 cement: 2.94 sand: 2.9 gravel: 0.48 water (mix design of PT. Rudy Jaya Beton 2017 report). for FAS 0.6, the ratio was 1 cement: 2.52 Sand: 3.74 gravel: 0.59 water (mix design CV. Dua Putri Bersaudara 2017 report). The 
sample of concrete was made in a tube with diameter 3.8 $\mathrm{cm}$ and thickness $1 \mathrm{~cm}$.

\section{B. Finding Consistency Time of Specimen}

The parameter which is used for water retention measurement was time of consistency water content on specimen (t1). The specimen was submerged in water in length of time varies until obtain time of specimen saturated.

\section{Finding Consistency Time of Filter Paper}

The specimen was submerged until saturated (t1), and then it was removed and wiped until the surface was dry. Clip of filter paper Whatman No.42 that has been protected by ordinary filter paper between two specimens. Then the two specimens were tied up with rubber and wrapped in plastic in order not to change the temperature so that the water content was constant ( $\mathrm{t} 2$ ).

\section{Water Retention Measurement}

Method of measurement water retention based on ASTM D5298-19. The First step was specimen immersed with immersion duration (t1). The second step search of dry filter paper weight, then insert filter paper in between two of the specimen, the specimen surface in a dry state. After filter paper contact with specimen, be searched of filter paper weight to obtain water content. Value of water retention can be obtain from water content data which were plotted on ASTM D5298-19 calibration graph and calibration filter paper method of some author, source Indarto (1991) and Indarto (2012).

\section{E. Calculation of Water Retention with Saturated Salt in Dessicator}

This stage was the same as the filter paper that was preceded by finding time of consistency of specimen water content in each FAS. After obtaining the consistency time of the specimen, the sample which has been in the oven for 24 hours were injected with water as much as the sample reach the consistency. Then they were put in a dessicator containing saturated salt and wait until the sample got stability of water content.

\section{F. Porosity Test}

Porosity is the ratio of empty volume inside a solid with solid volume. To find concrete porosity values based on ASTM C 642-90, as follows:

$$
\text { Porosity }=\frac{\mathrm{Wsa}-\mathrm{Wd}}{\mathrm{Wsa}-\mathrm{Wsw}} \times 100 \%
$$

where :

Wsa = weight of water saturated specimen in air (gr),

Wsw = weight of water saturated specimen in water (gr),

$\mathrm{Wd}=$ weight of specimen has been in the oven at $105^{\circ} \mathrm{C}$ for 24 hours (gr).

\section{G. Ultrasonic Pulse Velocity (UPV) Test}

UPV test based on ASTM C597-97, in which the PV test works in principle to transform wave of energy electricity generated by pulse generator sender transducer or transmitter $(\mathrm{T})$ into mechanical energy waves which then propagate to the concrete. After arriving at the receiving transducer or receiver (R), wave energy is converted back into electrical energy wave then pass through amplifier, then displayed in units of travel time. Ultrasonic wave velocity on concrete can be found by the equation:

$$
V=L / T
$$

where:

$\mathrm{V} \quad=$ ultrasonic wave velocity $(\mathrm{km} / \mathrm{sec})$;

$\mathrm{L} \quad=$ mileage $(\mathrm{mm})$; and

$\mathrm{T} \quad=$ time of ultrasonic wave (seconds).

\section{H. Permeability Test}

The permeability test is used to determine the potentiality of concrete to pass water through the pores. The permeability of the concrete is also influenced by the distribution of the grain size of the cement or the fineness of the cement grains. The using of coarser cement grain has a higher level of porosity than using a finer grain size of cement. Commonly, it can be argued that concrete with lower permeability will have better compressive strength than high permeability concrete.

\section{Compressive Strength Test}

Based on SNI 03-1974-2011, the definition of compressive strength is the amount of load per unit area, which causes the concrete specimen destroyed when burdened with a certain press force from the press machine. The compressive strength can be found by the equation:

$$
\text { Concrete Compressive Strength }=\text { P } / \text { A }(\mathrm{kg} / \mathrm{cm} 2)
$$

where :

$$
\mathrm{P}=\text { maximum load }(\mathrm{kg}) \text {; and }
$$

$\mathrm{A}=$ cross-sectional area $(\mathrm{cm} 2)$.

\section{RESULT AND DISCUSSION}

\section{A. Water Retention}

\section{1) Specimen of Concrete with Filter Paper Water-Cement} Ratio 0.5

Consistency time of specimen occurred in the soaking for 12 days with the water content reached $10.77 \%$. While the filter paper consistency occurred on the 1st day or during the 24 hours. Based on the data, the graph plot of water retention was obtained. It is shows in Figure $\mathbf{3}$ with maximum water content of $186.24 \%$ with a capillary height of 0.13 meters. Figure 2 shows the combination of the result of research and Scheneider \& Dora M.N.S's result, that the pattern of plot is similar, but the water content is higher than Van Genuchten's Dora's curve. It may be caused by different material composition. Concrete with symbol C-15 was used by Van Genuchten to find water retention. Concrete C-15 is combination of CEM 1 that consists of carbonat, calcareous aggregates, and super plasticizer. That composition was assumed has tiny pores. In addition, Dora's research that used cement paste has tiny pores too. 


\section{2) Specimen of Concrete with Filter Paper Water-Cement} Ratio 0.6

Consistency time of the specimens occurred in the immersion for 12 days with the water content reached $13.48 \%$. While the filter paper consistency occurred on the third day. Based on the data, the graph plot of water retention was obtained. It is shown in Figure 4 with a maximum water content of $201.84 \%$ with 0.08 meters capillary height.

3) Specimen of Concrete with Saturated Salt $\mathrm{KCl}, \mathrm{H}_{2} \mathrm{SO}_{4}$, and $\mathrm{NaCl}$ (water-cement ratio 0.5)

The maximum water content for saturated salt $\mathrm{KCl}$, $\mathrm{H}_{2} \mathrm{SO}_{4}$, and $\mathrm{NaCl}$ was $11.95 \%, 12.36 \%$, and $12.52 \%$ respectively. While the height of capillary was $12.76 \mathrm{~m}$, $11.83 \mathrm{~m}$, and $11.5 \mathrm{~m}$, which are shown in Figure 5, 6, and 7.

4) Specimen of Concrete with Saturated Salt $\mathrm{KCl}, \mathrm{H}_{2} \mathrm{SO}_{4}$, and $\mathrm{NaCl}$ (water-cement ratio 0.6)

The maximum water content for the saturated salt $\mathrm{KCl}$, $\mathrm{H}_{2} \mathrm{SO}_{4}$, and $\mathrm{NaCl}$ were $14.92 \%, 11.79 \%$, and $14.23 \%$. While the capillary height were $75 \mathrm{~m}, 130.42 \mathrm{~m}$, and 85,7 $\mathrm{m}$, which is shown in Figure 8, 9, and 10. From the water retention graph above, either using filter paper or saturated salt in desiccator with WCR 0.5 and WCR 0.6 were plotted in one graph and can be seen in Figure 11. From the graph, we can conclude that the use of saturated salt in dessicator is able to validate water retention calculation with filter paper Whatman No.42.

B. Correlation Among Water Retention, Porosity, UPV, Permeability, and Compressive Strength

The recapitulation of concrete test series at WCR 0.5 and 0.6 respectively can be seen in Table $\mathbf{1}$ and Table 2 . Characteristic of water retention on concrete is if water content in concrete is high, so the water retention is low. If water content in concrete is low, the water retention is high.

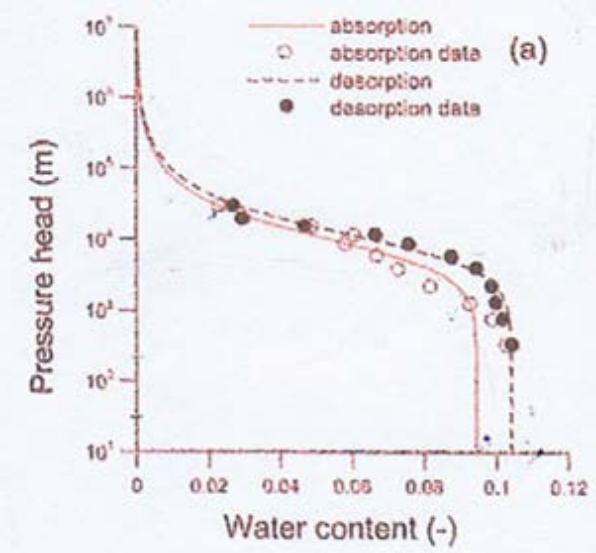

Figure 1. Water retention curves for concrete C-15-A (a) and mortar M1 (b). (Schneider, 2012)

TABLE 1.

CALIBRATION GRAPH OF SATURATED SALt NACL ON CONCRETE (WCR 0.5)

\begin{tabular}{ccccccc}
\hline \hline Kode Benda Uji & Kadar Air Wc (\%) & Porosit as (\%) & pF & UPV (km/s) & Permeabilitas $\mathbf{1 0}^{-6} \mathbf{m}^{2}$ & Kuat Tekan (Mpa) \\
\hline 1 & 5,338 & 12,141 & 6,600 & 3,83 & 0,503 & 17,83 \\
2 & 5,284 & 12,077 & 6,604 & 3,85 & 0,08 & 18,68 \\
\hline \hline
\end{tabular}

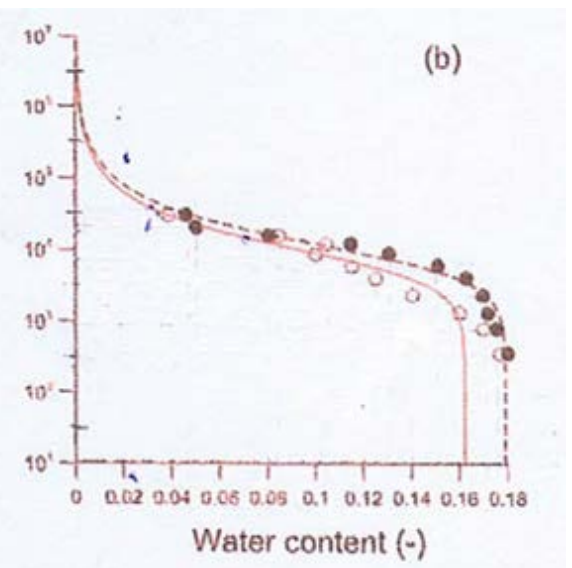

It is proved by the result of concrete WCR 0.5 that water content $1.83 \%$ has water retention $728.426 \mathrm{Kpa}$ and water content $186.24 \%$ has water retention of $1.32 \mathrm{Kpa}$, whereas in mortar WCR 0.6 that water content of $2.8 \%$ has water retention $616.197 \mathrm{Kpa}$ and water content of $201.84 \%$ has water retention $0.85 \mathrm{Kpa}$.

In a series of porosity test, UPV, permeability and compressive strength in outline, if it is related to water retention value, it can be concluded that the water retention value is high, then UPV and compressive strength are high, but the porosity and the permeability are low. And if water retention is low, the UPV and the compressive strength will decrease, but porosity and permeability are higher. This explanation can be seen in Figure 12 to Figure 17.

\section{CONCLUSION}

In this paper, we would like to present water retention measurement using filter paper Whatman No.42 on concrete. The calculation method of water retention using Filter paper Whatman No.42 can be used on concrete material. The calculation of water retention with saturated salt solution method in dessicator can validate the calculation of water retention with filter paper Whatman No.42, but it's only limited to voltage of less than -2500 $\mathrm{kPa}$. I this study, there were test of porosity, UPV, compressive strength, and permeability. The results of the test showed that water retention was directly proportional to wave propagation and compressive strength. This means that if the value of water retention is higher, so wave velocity and compressive strength are higher too. Conversely, water retention was inversely proportional to pore content, water content, and permeability. In this study, it was seen that the pore level in concrete was very influential on water retention. 


\begin{tabular}{lllllll}
\hline \hline 3 & 5,460 & 12,439 & 6,591 & 3,79 & 0,809 & 13,76 \\
4 & 5,646 & 14,273 & 6,577 & 3,56 & 0,756 & 13,64 \\
\hline \hline
\end{tabular}

TABLE 2.

CALIBRATION GRAPH OF SATURATED SALt NACL ON CONCRETE (WCR 0.6)

\begin{tabular}{ccccccc}
\hline \hline Kode Benda Uji & Kadar Air Wc (\%) & Porosit as (\%) & $\mathbf{p F}$ & $\mathbf{U P V}(\mathbf{k m} / \mathbf{s})$ & ${\text { Permeabilitas } \mathbf{1 0}^{-6} \mathbf{m}^{2}}^{\text {Kuat Tekan (Mpa) }}$ \\
\hline 1 & 5,243 & 12,134 & 6,607 & 3,64 & 0,21 & 13,70 \\
2 & 5,646 & 12,878 & 6,577 & 3,64 & 0,289 & 11,15 \\
3 & 5,087 & 13,694 & 6,543 & 3,63 & 0,323 & 10,53 \\
4 & 5,246 & 13,981 & 6,532 & 3,56 & 0,472 & 10,08 \\
\hline \hline
\end{tabular}

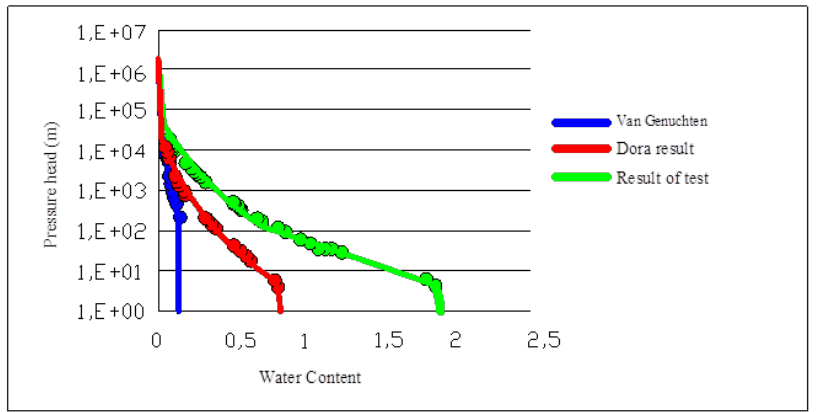

Figure 2. Comparison between water retention of cement paste WCR 0.5 with water retention of concrete C-15-A (Schneider et al., 2012), and Dora (2017)

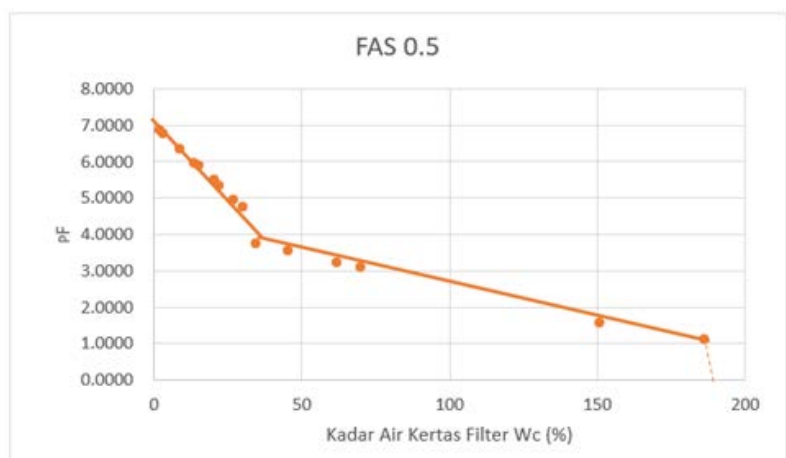

Figure 3. Calibration graph of filter paper Whatman no.42 on concrete (WCR 0.5)

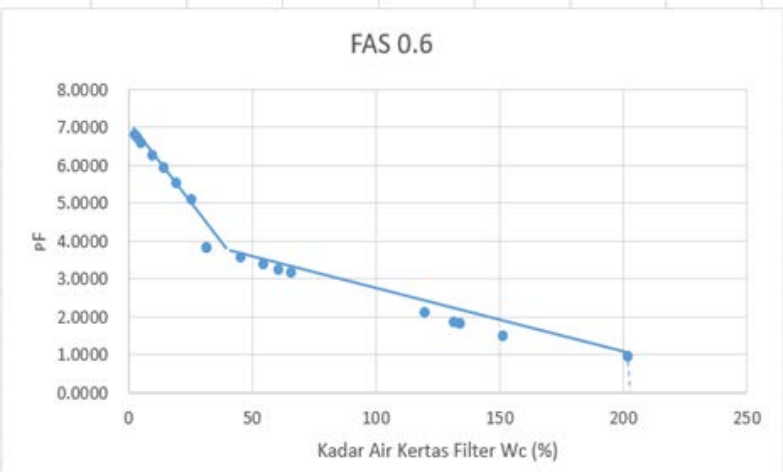

Figure 4. Calibration graph of filter paper Whatman no.42 on concrete (WCR 0.6)

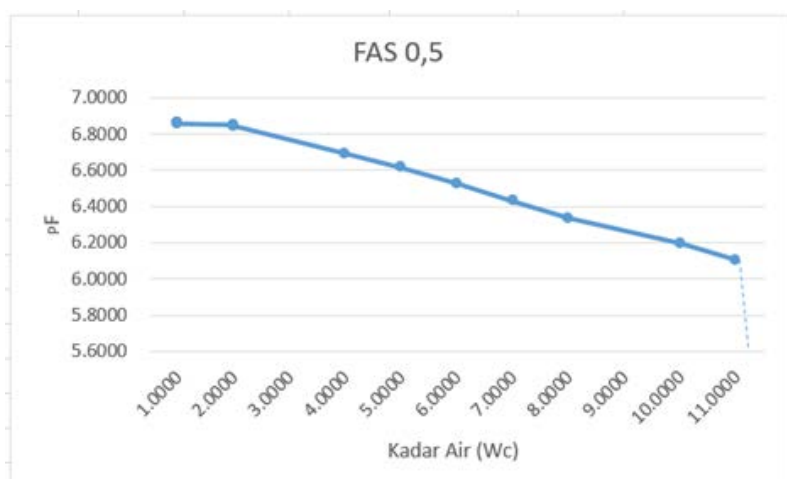

Figure 5. Calibration graph of saturated salt $\mathrm{KCl}$ on concrete (WCR 0.5)

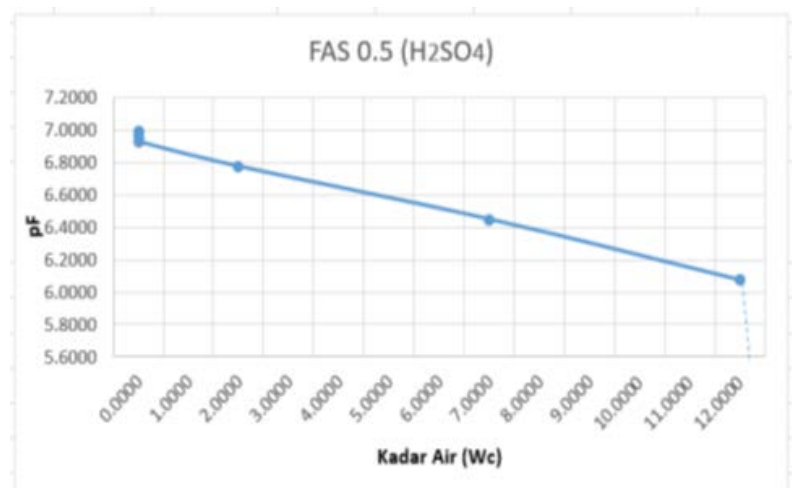

Figure 6. Calibration graph of saturated salt H2SO4 on concrete (WCR $0.5)$

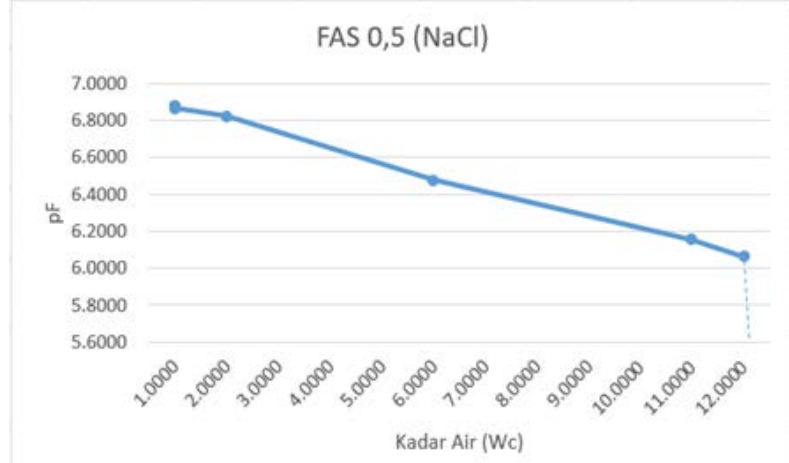

Figure 7. Calibration graph of saturated salt $\mathrm{NaCl}$ on concrete (WCR 0.5) 


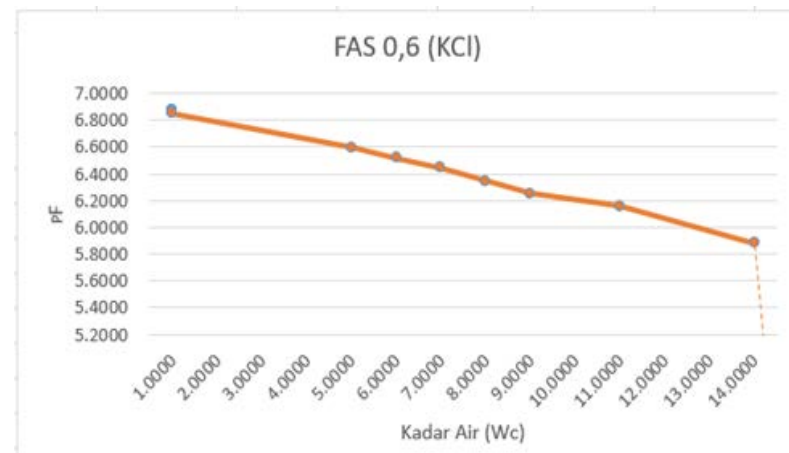

Figure 8. Calibration graph of saturated salt KClon concrete (WCR 0.6)

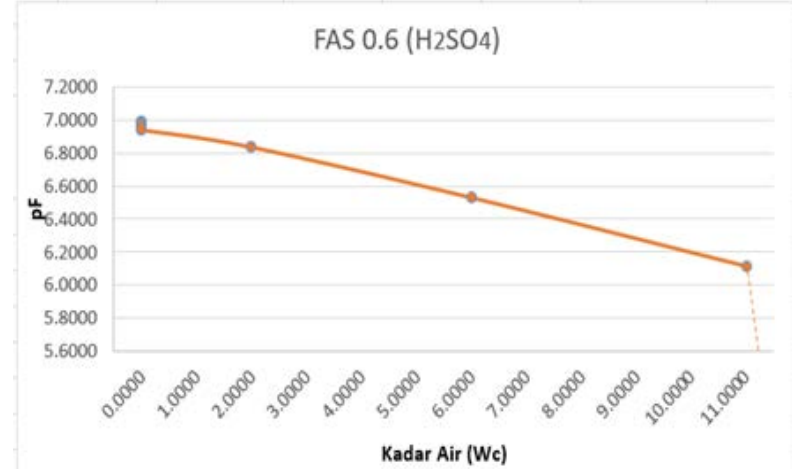

Figure 9. Calibration graph of saturated salt $\mathrm{H}_{2} \mathrm{SO}_{4}$ on concrete (WCR 0.6)

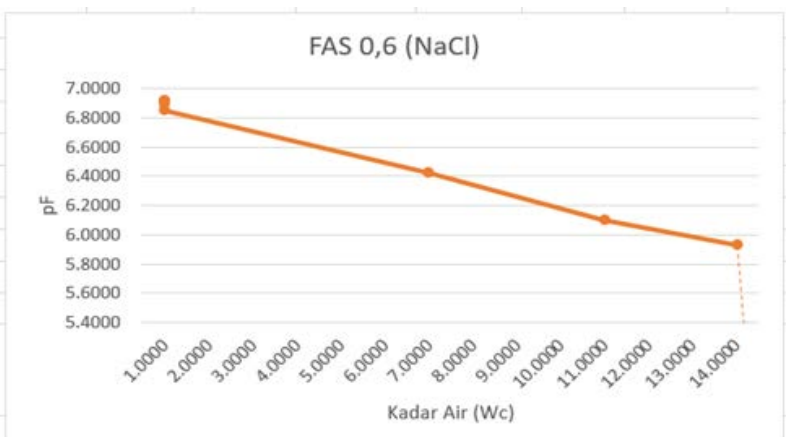

Figure 10. Calibration graph of saturated salt $\mathrm{NaCl}$ on concrete (WCR 0.6)

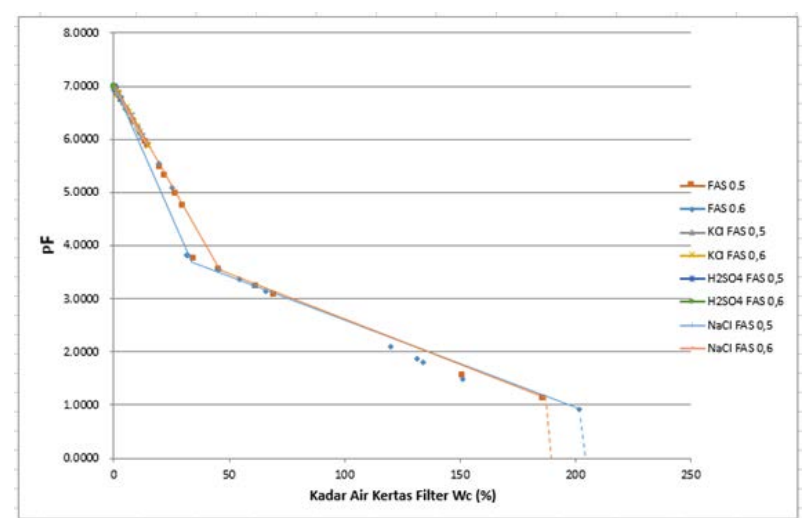

Figure 11. Calibration graph of filter paper and saturated salt in dessicator on concrete

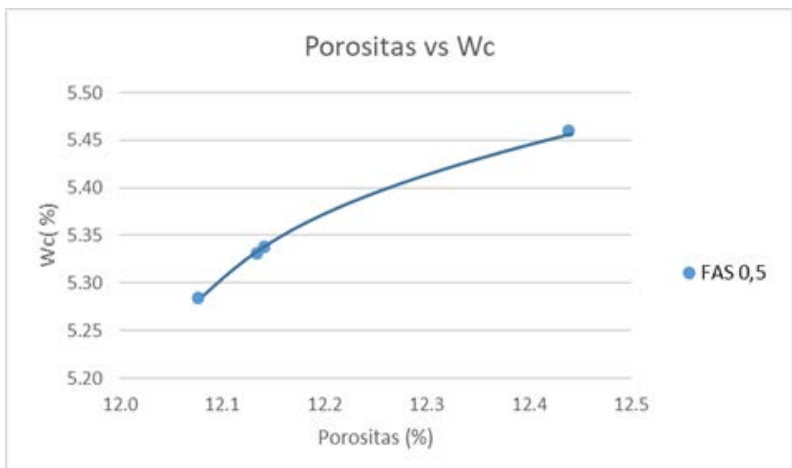

Figure 12. Comparison graph between porosity and water content on concrete (WCR 0.5)

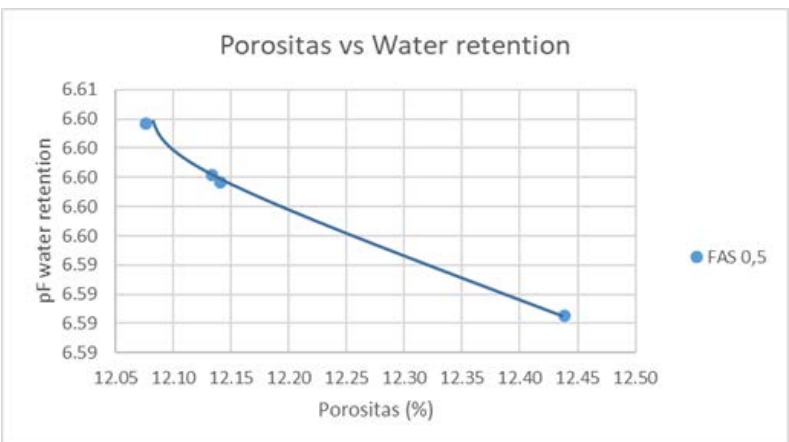

Figure 13. Comparison graph between porosity and water retention on concrete (WCR 0.5)

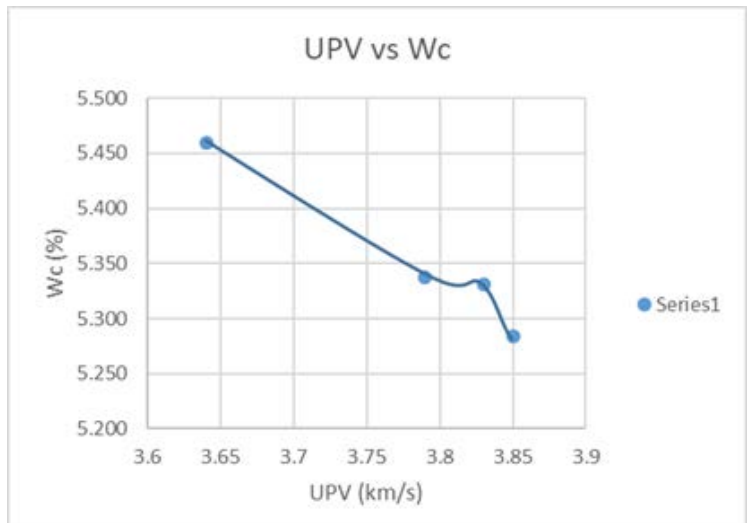

Figure 14. Comparison graph between UPV and water content on concrete (WCR 0.5)

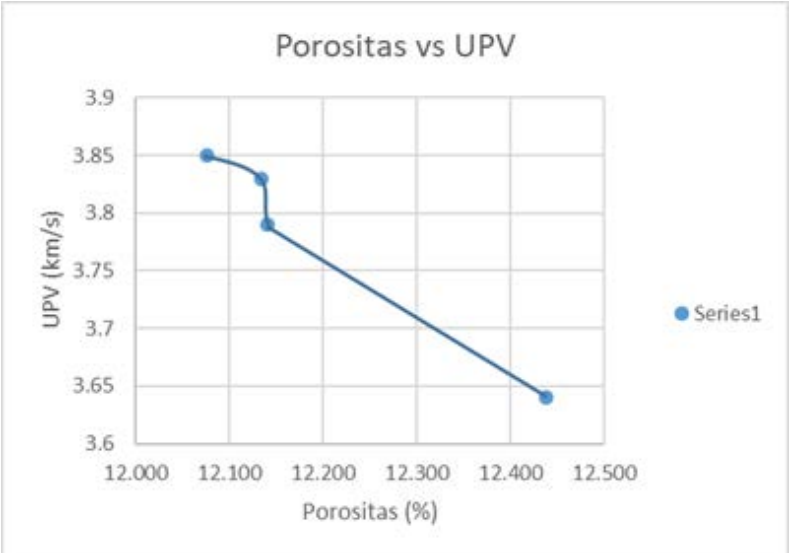

Figure 15. Comparison graph between porosity and UPV on concrete (WCR 0.5) 
The $4^{\text {th }}$ International Seminar on Science and Technology August $9^{\text {th }}$ 2018, Postgraduate Program Institut Teknologi Sepuluh Nopember, Surabaya, Indonesia

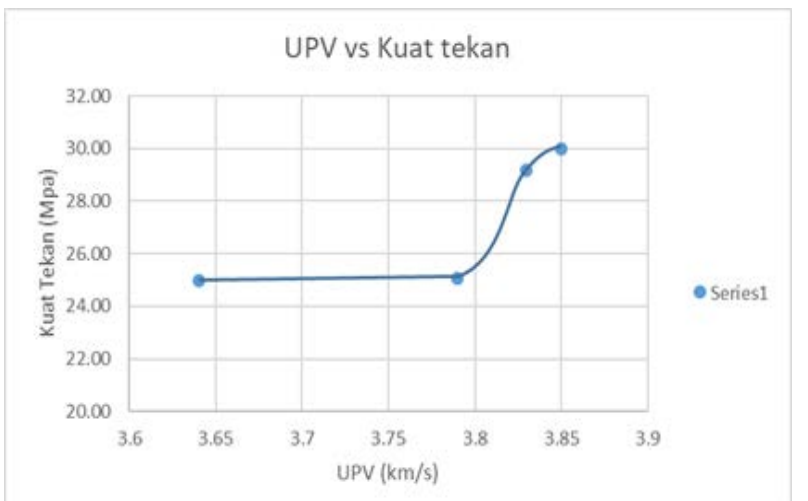

Figure 16. Comparison graph between UPV and press strength on concrete (WCR 0.5)

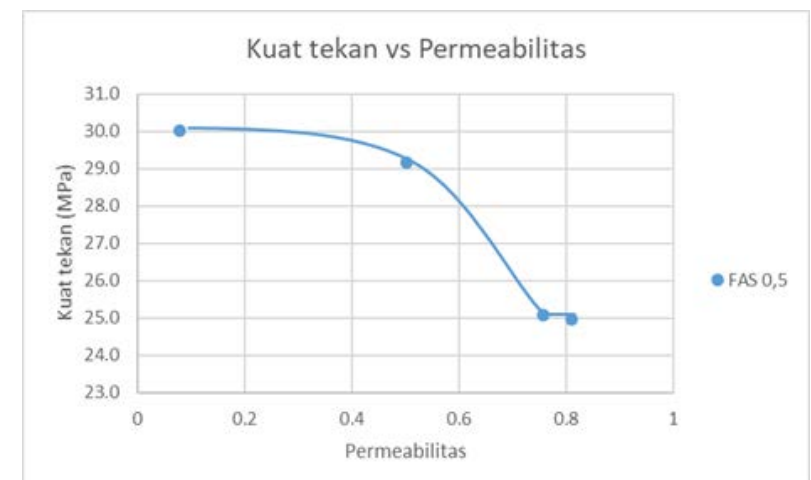

Figure 17. Comparison graph between press strength and permeability on concrete (WCR 0.5) 